\title{
The MASCC/ISOO Mucositis Guidelines 2019 Update: introduction to the first set of articles
}

\author{
Sharon Elad ${ }^{1}$
}

Received: 3 April 2019 / Accepted: 22 May 2019 / Published online: 8 July 2019

(C) Springer-Verlag GmbH Germany, part of Springer Nature 2019

The Multinational Association of Supportive Care in Cancer/ International Society of Oral Oncology (MASCC/ISOO) is a partnership between two professional organizations focusing on research and education concerning all aspects of supportive care for cancer patients. These organizations collaborate closely regarding oral complications secondary to cancer or cancer therapy, including the common complication mucositis, which can affect any part of the gastrointestinal tract, depending on the type of cancer and therapy.

While the primary goal is to cure cancer, patients expect to be able to tolerate the complications associated with cancer therapy without compromising immediate and long-term quality of life. Accordingly, health care providers need safe and efficient treatment modalities to manage the complications of cancer therapy.

To this end, a tremendous worldwide research effort has been made to study interventions for mucositis, creating a massive body of literature. It is clear that clinicians and patients would benefit from a systematic assessment of the evidence that identifies the best available agents. Therefore, the Mucositis Study Group (MSG) of MASCC/ISOO decided to create a guide for clinicians, aiming to improve patient care.

The MSG includes health care professionals from the numerous disciplines involved in the care of cancer patients. The collaboration between physicians, dentists, nurses, psychologists, physical therapists, speech therapists, and pharmacists, as well as basic science researchers, provides the MSG with a wide range of perspectives and allows an in-depth assessment of the scientific evidence.

The first set of clinical practice guidelines for the management of mucositis was published in 2004 [1] and updated in

Sharon Elad

selad@urmc.rochester.edu

1 Oral Medicine, Eastman Institute for Oral Health, University of Rochester Medical Center, 625 Elmwood Ave.,

Rochester, NY 14620, USA
2007 and $2014[2,3]$. Due to the broad spectrum of interventions for the management of mucositis, the MSG of MASCC/ ISOO divided the topic into 8 sections. During the current systematic review and guideline update, all sections used the same methods and communication between the sections ensured that there were no gaps in the coverage of the literature.

The Methods paper [4] details the meticulous process of systematic review and analysis of the evidence. During this systematic review, the evidence for each intervention was weighted and interventions with the strongest level of evidence were listed as an optional therapy for specific patient populations. The rigorous methods used to produce these guidelines are the key to their robustness. Generally, the same methods employed in previous editions of mucositis clinical practice guidelines were used, although some changes were made. These changes reflect the weight given to clinical trials with the best study design and with the strongest power.

This volume of JSCC includes the first series of papers generated as part of this guideline update, and several types of interventions for oral mucositis will be presented, including anti-inflammatory agents [5], photobiomodulation [6], vitamins, minerals, and nutritional supplements [7], and protocols categorized as basic oral care [8]. An entire paper was dedicated to interventions for the management of gastrointestinal mucositis, i.e., affecting areas in the gastrointestinal tract outside the oral cavity [9]. Some guidelines are new statements whereas other guidelines may be considered as enhancements or clarifications of previous guidelines. Most notably, major changes were introduced in the photobiomodulation guideline paper, a rapidly growing area of research.

Importantly, this guideline update did not only review new literature since 2011 (cut-off date of previous guideline update); rather, the analysis included all publications. The merging of previously published and newly published clinical trials while analyzing the quality of evidence prior to determining the guideline category is a unique addition to the guidelines methods and required a tremendous effort. 
Targeted therapy, which has become a mainstay in cancer treatment, was not included in this set of guidelines. This was based on the need to prioritize updating the existing guidelines and later expanding them to include interventions for mucositis-associated with targeted therapy and immunotherapy.

While clinical trials provide evidence on the efficacy of interventions for mucositis, there has also been extensive research on the pathogenesis of mucositis. This research will help identify key players in the development of mucositis that will become targets of future therapeutic interventions. Therefore, alongside the systematic review of clinical interventions, the MSG also reviewed systematically advances in the understanding of the pathogenesis of mucositis [10]. This review builds on the systematic review of pathogenesis published by the MSG previously and presents the developments since then [11].

The complete set of guidelines on the management of mucositis will be available after the second batch of papers by the MSG is published in an upcoming volume of the JSCC. It is important to note that guidelines are not designed to dictate treatment for any particular patient or condition; they intend to provide detailed information about all available interventions with strong evidence supporting their use that should be considered by the clinician. The final treatment decision and implementation is up to the discretion of the treating clinician.

This project relies on the professionalism and devotion of MSG members who volunteered their knowledge and time. The group effort needed to achieve the ambitious goal of this project is enormous. As the leader of the MSG, I would like to take this opportunity to sincerely thank each and every member of the MSG who participated in this guideline update. Special thanks go to the MASCC President, Prof. Lalla, who served as a Chief Consultant; the MSG Vice-Chairs, Profs. Bossi and Cheng; and the Section Heads and Section Coheads who contributed to the respective guidelines publications. I am also grateful to the MASCC/ISOO leadership and staff for their support.

\section{Compliance with ethical standards}

Conflict of interest Prof. Elad serves as Chair of the Mucositis Study Group of MASCC/ISOO, and discloses no conflict of interest regarding the subject matter.

Per the MASCC Guidelines Policy, employees of commercial entities were not eligible to serve on the MASCC Guideline Panel. All authors completed a Conflict of Interest disclosure form and conflicts are disclosed in the guideline publications.

Disclaimer The MASCC/ISOO Mucositis Guidelines were developed to facilitate evidence-based management of mucositis. However, clinicians should always use their own judgement to make treatment decisions for individual patients. The guideline authors and MASCC/ISOO do not guarantee or take responsibility for clinical outcomes in individual patients.

\section{References}

1. Rubenstein EB, Peterson DE, Schubert M, Keefe D, McGuire D, Epstein J, Elting LS, Fox PC, Cooksley C, Sonis ST, Mucositis Study Section of the Multinational Association for Supportive Care in C, International Society for Oral Oncology (2004) Clinical practice guidelines for the prevention and treatment of cancer therapy-induced oral and gastrointestinal mucositis. Cancer 100:2026-2046

2. Keefe DM, Schubert MM, Elting LS, Sonis ST, Epstein JB, RaberDurlacher JE, Migliorati CA, McGuire DB, Hutchins RD, Peterson DE, Mucositis study section of the multinational Association of Supportive Care in C, the International Society for Oral Oncology (2007) Updated clinical practice guidelines for the prevention and treatment of mucositis. Cancer 109:820-831

3. Lalla RV, Bowen J, Barasch A, Elting L, Epstein J, Keefe DM, McGuire DB, Migliorati C, Nicolatou-Galitis O, Peterson DE, Raber-Durlacher JE, Sonis ST, Elad S, Mucositis Guidelines Leadership Group of the Multinational Association of Supportive Care in C, International Society of Oral Oncology (2014) MASCC/ISOO clinical practice guidelines for the management of mucositis secondary to cancer therapy. Cancer 120:1453-1461

4. Ranna V, Cheng K, Castillo D, Porcello L, Vaddi A, Lalla R, Bossi P, Elad S (2019) Development of the MASCC/ISOO clinical practice guidelines for mucositis: an overview of the methods support care. Support Care Cancer https://doi.org/10.1007/s00520-01904891-1

5. Ariyawardana A, Cheng K, Kandwal A, Tilly V, Al-Azri A, Galiti D, Chiang K, Vaddi A, Ranna V, Nicolatou-Galitis O, Lalla R, Bossi P, Elad S (2019) Systematic review of antiinflammatory agents for the management of oral mucositis in cancer patients and clinical practice guidelines. Support Care Cancer https://doi.org/10.1007/s00520-019-04888-w

6. Zadik Y, Arany P, Fregnani E, Bossi P, Antunes H, Bensadoun R-J, Gueiros L, Majorana A, Nair R, Ranna V, Tissing W, Vaddi A, Lubart R, Migliorati C, Lalla R, Cheng K, Elad S (2019) Systematic review of photobiomodulation for the management of oral mucositis in cancer patients and clinical practice guidelines. Support Care Cancer https://doi. org/10.1007/s00520-019-04890-2

7. Yarom N, Hovan A, P. B, Ariyawardana A, Jensen S, Gobbo M, Hazboun H, Kandwal A, Majorana A, Ottaviani G, Pentenero M, Nasr N, Rouleau T, Skripnik Lucas A, Treister N, Zur E, Ranna V, Vaddi A, Cheng K, Barasch A, Lalla R, Elad S (2019) Systematic review of natural and miscellaneous agents for the management of oral mucositis in cancer patients and clinical practice guidelines part 1: vitamins, minerals and nutritional supplements. Support Care Cancer https://doi.org/10.1007/s00520-019-04887-x

8. Hong C, Gueiros L, Fulton J, Cheng K, Kandwal A, Galiti D, FallDickson J, Johansen J, Ameringer S, Kataoka T, Weikel D, Eilers J, Ranna J, Vaddi A, Lalla R, Bossi P, Elad S (2019) Systematic review of basic oral care for the management of oral mucositis in cancer patients and clinical practice guidelines. Support Care Cancer https://doi.org/10.1007/s00520-019-04848-4

9. Bowen J, Gibson R, Coller J, Blijlevens N, Bossi P, Al-Dasooqi N, Bateman E, Chiang K, De Mooji C, Mayo B, Stringer A, Tissing W, Wardill H, Van Sebille Y, Ranna V, Vaddi A, Lalla R, Cheng K, Elad S (2019) Systematic review of agents for the management of cancer gastrointestinal mucositis and clinical practice guidelines. Support Care Cancer https://doi.org/10.1007/s00520-019-04892-0

10. Bowen J, Al-Dasooqi N, Bossi P, Wardill H, Van Sebille Y, Al-Azri A, Bateman E, Correa M, Raber-Durlacher J, Kandwal A, Mayo B, Nair R, Stringer A, ten Bohmer K, Thorpe D, Lalla R, Sonis S, 
Cheng K, Elad S (2019) The pathogenesis of mucositis: updated perspectives and emerging targets. Support Care Cancer https://doi. org/10.1007/s00520-019-04893-Z

11. Al-Dasooqi N, Sonis ST, Bowen JM, Bateman E, Blijlevens N, Gibson RJ, Logan RM, Nair RG, Stringer AM, Yazbeck R, Elad S, Lalla RV, Mucositis Study Group of the Multinational Association of Supportive Care in Cancer/International Society of
Oral Oncology (2013) Emerging evidence on the pathobiology of mucositis. Support Care Cancer 21:3233-3241

Publisher's note Springer Nature remains neutral with regard to jurisdictional claims in published maps and institutional affiliations. 